\title{
AOTD-Seminar in Wiesbaden
}

Klaus Wenda

Am 15. Juni 2018 fand im Kurhaus Wiesbaden das 23. Mainz/Wiesbadener AOTrauma-Symposium unter der Leitung von Prof. Klaus Wenda und Prof. Pol Rommens statt. Thema war die Frage „Wie stabil muss die Osteosynthese sein?"

Zwölf renommierte Experten stellten für die Regionen des Bewegungsapparates dar, wann man sich bei der Osteosynthese auf die biologische Abstützung verlassen kann und wann hohe Stabilität meist unter einer gewissen Beeinträchtigung der Vitalität erforderlich ist. Die Diskussion mit den 68 Teilnehmenden war der Thematik entsprechend lebhaft und kontrovers.

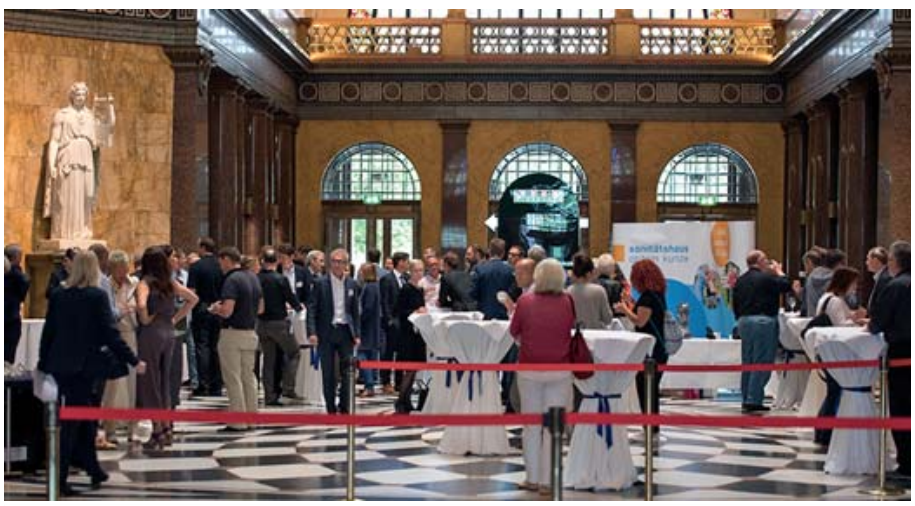

Abb. 1 Veranstaltungsort Kurhaus Wiesbaden. (C) Klaus Wenda

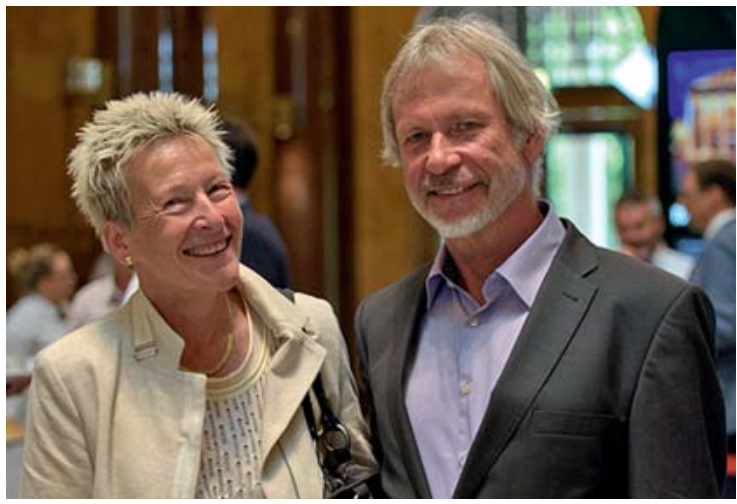

- Abb. 3 Die langjährige leitende Oberärztin Dr. Corinna Plieschnegger mit Klaus Wenda. @ Klaus Wenda
Im Rahmen des Symposiums erfolgte auch die Übergabe des Staffelstabes von Prof. Klaus Wenda an Prof. Sebastian Wutzler als Chef der Klinik für Unfall-, Hand und Orthopädische Chirurgie der Wiesbadener Helios Dr. HorstSchmidt-Kliniken. Sebastian Wutzler war zuvor Leitender Oberarzt der Unfallchirurgie der Goethe-Universität Frankfurt.

\section{Bibliografie}

DOI https://doi.org/10.1055/a-0749-4544

OP-JOURNAL 2018; 34: 340 @ Georg Thieme Verlag KG Stuttgart · New York ISSN 0178-1715

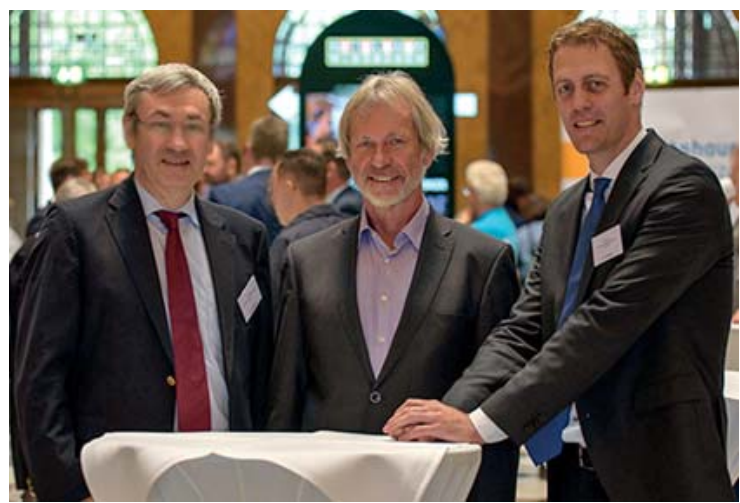

- Abb. 2 Seminarleiter Rommens, Wenda und Wutzler. (c) Klaus Wenda

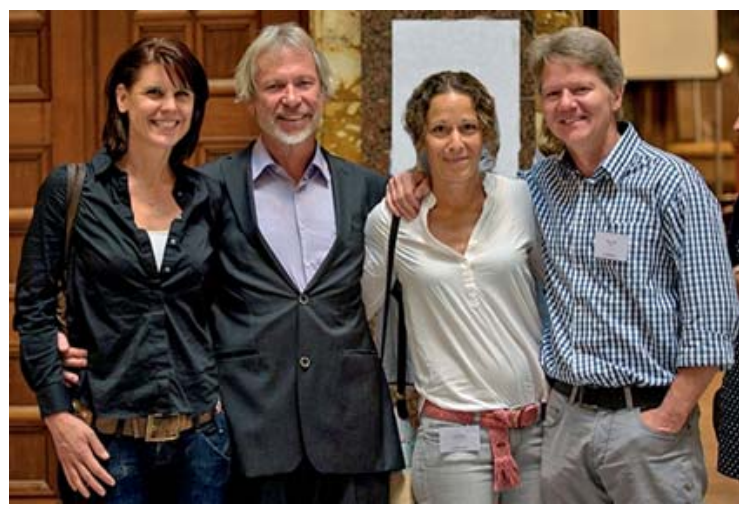

- Abb. 4 Barbara Immesberger, Klaus Wenda, Lena Spieker und Volker Hertel. @ Klaus Wenda 